\title{
Pharmacist medication review decreased death, and number and cost of drugs prescribed for residents in nursing homes
}

Furniss L, Burns A, Craig SK, et al. Effects of a pharmacist's medication review in nursing homes. Randomised controlled trial. Br J Psychiatry 2000 Jun;176:563-7.

\author{
QUESTION: Does pharmacist medication review (PMR) affect quality of care and \\ number of drugs prescribed in nursing homes (NHs)?
}

\section{Design}

Randomised (allocation not concealed*), unblinded*, controlled trial with a 4 month observation phase, a 4 month intervention phase, and follow up at 8 months.

\section{Setting}

14 NHs, south Manchester, UK.

\section{Participants}

$330(78 \%)$ of 424 residents participated (mean age $81 \mathrm{y}$, $73 \%$ women). $294(89 \%)$ residents were available at 4 months follow up, and $276(84 \%)$ at 8 months follow up.

\section{Intervention}

NHs were paired according to number of beds, resident mix, and status; from each pair $1 \mathrm{NH}$ was allocated to PMR $(n=158)$, and 1 to no review $(n=172)$. After a 4 month observation period, a pharmacist visited the intervention NHs and for each resident recorded types and amounts of drugs used, assessed the use of any neuroleptic drugs, and suggested changes. 3 weeks after the intervention, NHs were checked for acceptance of the suggestions and any complications from medication changes.

\section{Main outcome measures}

Changes in medication, mortality, mental state (assessed by Mini-Mental State Examination [MMSE], Geriatric Depression Scale [GDS], Brief Assessment Schedule Depression Cards [BASDEC], and Crichton-Royal Behaviour Rating Scale [CRBRS]), and costs.

\section{Main results}

The pharmacist made 261 recommendations resulting in 144 actual medication changes. 128 (81\%) residents in the group with PMR had medication changes (mean 2.5 changes, range $0-7$ ). During the intervention phase, the NHs with PMR had fewer deaths and a greater decrease in number of drugs prescribed per resident than NHs with no review $(p=0.03)$ (table). There were no significant changes in MMSE, GDS, and BASDEC scores. There was a significant increase over the 2 phases in the mean CRBRS score for the group with PMR. Medication costs per resident during the intervention phase were reduced by $£ 27.47$ (from $£ 159.01$ to $£ 131.54$ ) for the NHs with PMR and £1.29 (from $£ 142.53$ to £141.24) for the NHs with no review. The mean number of drugs taken by residents at 4 months was 5.1 for the group with PMR and 4.5 for the group with no review $(\mathrm{p}=0.03)$, and at 8 months was 4.2 and 4.4 , respectively $(\mathrm{p}=0.07)$

\section{Conclusion}

For residents in nursing homes, pharmacist medication review decreased death, and number and cost of drugs prescribed.

*See glossary.

Pharmacist medication review (PMR) $v$ no review for mortality and mean drugs prescribed in nursing home residents for 4 months before and after review

\begin{tabular}{lllll}
\hline Outcomes & PMR & No review & RRI (95\% Cl) & NNH \\
$\begin{array}{l}\text { Death } 0 \text { to } 4 \text { months } \\
\text { (observation phase) }\end{array}$ & $14 \%$ & $8 \%$ & $71 \%(-8$ to 220$)$ & Not significant \\
\hline $\begin{array}{c}\text { Death } 5 \text { to } 8 \text { months } \\
\text { (intervention phase) }\end{array}$ & $4 \%$ & $9 \%$ & $67 \%(7$ to 88$)$ & NRT (Cl) \\
\hline
\end{tabular}

†Abbreviations defined in glossary; RRI, RRR, NNH, and NNT calculated from data in the article.

\section{COMMENTARY}

Pharmacotherapy is a substantial issue in geriatric care due to the many medical problems prevalent in this population. Frail elderly people requiring long term care are often prescribed multiple medications to address their numerous clinical conditions. A long standing concern in this population is less than optimal medication use which can compromise an elderly person's clinical condition and function. Pharmacist based interventions have been shown to add quality of care and decrease overall costs. ${ }^{12}$ In this study by Furniss $e t a l$, pharmacist medication review was shown to significantly affect costs, number of medications, and mortality in the treatment phase of the study.

Medication review is relatively simple and low cost, and has been mandated as a necessary component of geriatric care in most jurisdictions in North America. It is important to emphasise that pharmacists already have the required skills to do medication reviews and fill this important initial step.

The economic impact was a reduction in overall costs of care by $£ 178$ in the intervention group versus $£ 16$ in the control group. Medication cost reduction, although favouring the intervention group, did not drive this difference nor motivate the interventions. Most suggestions involved removing medications no longer indicated as necessary, or changing to safer alternatives. The changes resulted in cost savings through decreased hospital admission rates. The study indicates a benefit in clinical outcomes requiring fewer healthcare resources per patient, and is supported by the significant reduction in mortality.

It is uncertain if continuing the intervention beyond 4 months would increase the degree of benefit achieved or if it would be duplicated in a different patient mix. These results may be dependent on the level of participation of the pharmacist in a Medicines Administration Record review programme and their skill in identifying and addressing drug related problems. Overall, however, this study supports pharmacists taking an active, integral role as part of the geriatric healthcare team.

Allan Mills, BSc(Pharm), PharmD Baycrest Centre for Geriatric Care Toronto, Ontario, Canada

1 Bjornson DC, Hiner WO Jr, Potyk RP, et al. Effect of pharmacists on health care outcomes in hospitalized patients. Am J Hosp Pharm 1993;50:1875-84.

2 Hanlon JT, Weinberger M, Samsa GP, et al. A randomized, controlled trial of a clinical pharmacist intervention to improve inappropriate prescribing in elderly outpatients with polypharmacy. Am J Med 1996;100:428-37. 